\title{
KONTROLLI AUTOMATIK NË ROBOTIKË
}

\author{
Enea Kote*, Artur Prendi*
}

*Departamenti i Inxhinierive, Fakulteti i Shkencave të Aplikuara dhe Ekonomike, Albanian University

Adresë kontakti: eneakote@outlook.com,prendiartur@yahoo.com

\section{Përmbledhje}

Robotika është shkenca dhe teknologjia e robotëve, dizenjimit, prodhimit dhe përdorimit të tyre. Roboti është një manipulator i riprogramueshëm i dizenjuar për të lëvizur në mënyrë të specifikuar nëpërmjet lëvizjeve të programuara.

Në këtë projekt do të ndërtojmë një robot të lëvizshëm në mënyrë të pavarur, automatike. Kjo nënkupton që roboti do të jetë $\mathrm{i}$ aftë në njohjen e pengesave që do të hasë gjatë rrugës dhe shmangjen e tyre me sukses.

Fjalë çelës: Arduino, mikrokontroller, sensor ultrasonik, robot.

\section{AUTOMATIC CONTROL IN ROBOTICS}

\section{Abstract}

Robotics is the science and technology of robots, their design, production and use. The robot is a reprogrammable manipulator designed to move specifically through programmed movements.

In this project, we will build an independent, automatic mobile robot. This means that the robot will be able to recognize the obstacles it will encounter along the way and avoid them successfully.

Keywords: Arduino, microcontroller, ultrasonic sensor, Robot. 
Enea Kote, Artur Prendi

\section{Hyrje}

Në këtë projekt do të ndërtojmë një robot të lëvizshëm në mënyrë të pavarur, automatike. Kjo nënkupton që roboti do të jetë i aftë në njohjen e pengesave që do të hasë gjatë rrugës dhe shmangjen e tyre me sukses.

Mjeti më i mirë për të arritur këtë, është studimi i teorisë së kontrollit nëpërmjet së cilës mësohet se si të influencosh në sistemet dinamike të robotëve. Elementi kryesor që do t’i japë jetë këtij projekti, pra, do të mundësojë “shikimin” e këtij roboti do të jetë një sistem ultrasonik $[1,2]$. Ky aparat do të jetë i aftë në lëshimin dhe marrjen e valëve ultrasonike, si dhe matjen e distancës së valeve, e gjithë kjo do t'i mundësojë atij një skanim të territorit përpara dhe të kuptojë nëse është e mundur lëvizja përpara, apo duhet ndryshuar drejtimi i lëvizjes. Pjesa praktike e projektit konsiston në ndërtimin dhe kontrollin e këtij roboti me dy rrota të diferencuara dhe të pavarura nga njëra-tjetra. Kjo do t'i mundësojë atij lëvizjen në drejtimin drejtëvizor, kthimin e mënjanur në marrjen e kthesave si edhe lëvizjen mbrapa.

\section{Komponentët e robotit tonë}

1. Sensor ultrasonic

2. Arduino UNO

3. Kontrollues / Ndarës sinjali

4. Kasë pleksiglasi

5. 2 Motorë DC

6. 3 Rrota

7. Kasë dhe Bateri $4 \times 1.5 \mathrm{~V}$ (AA)

8. Çelës On / Off

9. Jumpers / Konektorë 

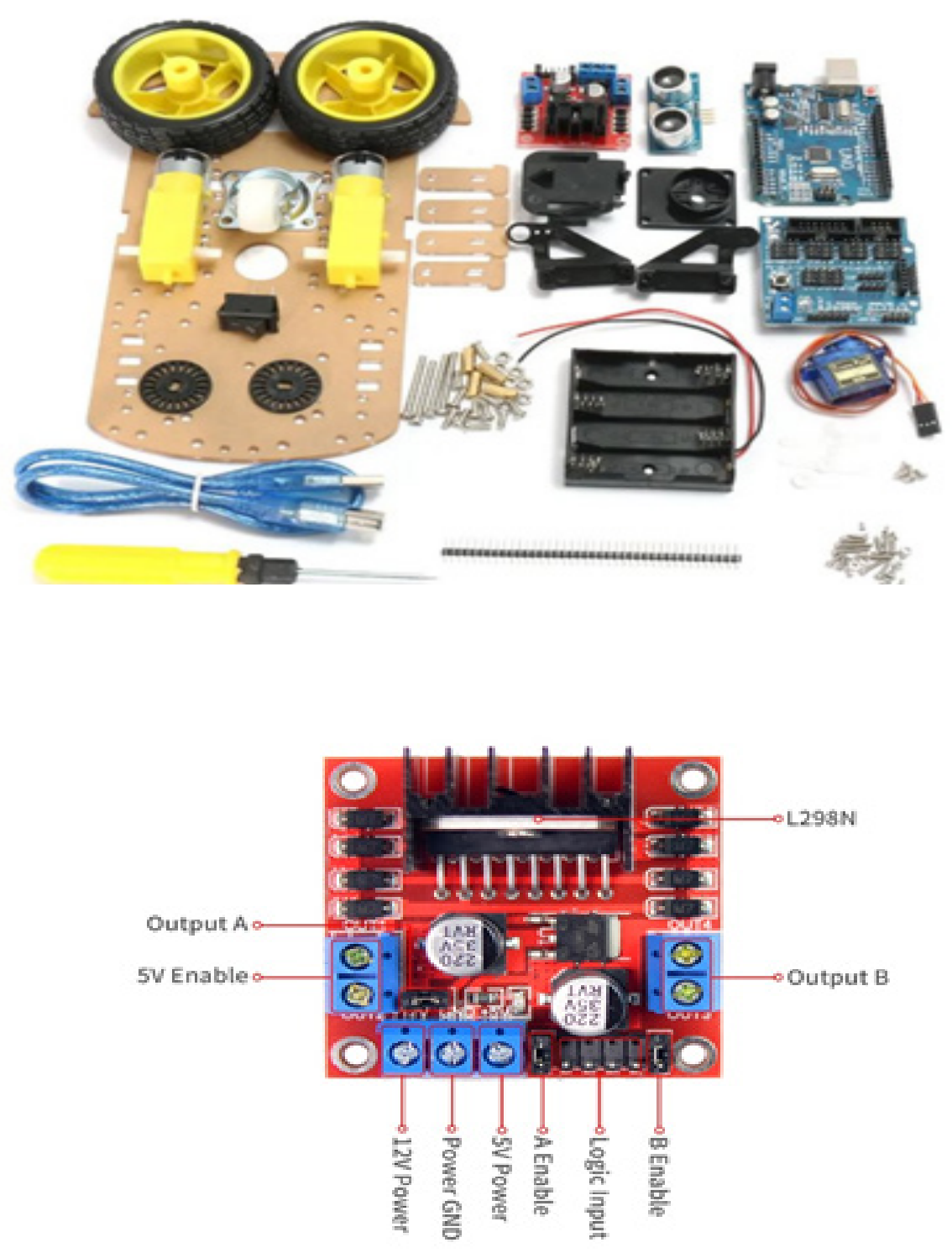

Fig. 1 Komponentët e robotit

Fig. 2 Moduli L298N

\section{Ndërtimi}

Njësia qendrore e robotit tonë do të jetë moduli i programueshëm Arduino Uno me një mikrokontroller Atmega328PU prej $20 \mathrm{MHz}$.

Moduli Arduino programohet nëpërmjet gjuhës së programimit Arduino [3, 4]. Roboti do ta marrë furnizimin me DC nga 4 bateri $1.5 \mathrm{~V}$ të lidhura në seri, të cilat na japin një total prej $6 \mathrm{~V}$ dhe janë të lidhura drejtpërdrejtë me shpërndarësin \kontrolluesin e fuqisë L298N. 
Enea Kote, Artur Prendi

Gjithashtu, qarku ndërpritet nga një çelës për të mundësuar ndezjen dhe fikjen e robotit. Nisur nga moduli kontrollues, 2 cifte nga $5 \mathrm{~V}$ do të lidhen drejt secilit nga motorrët e rrotave dhe do të mundësojë funksionimin e tyre.

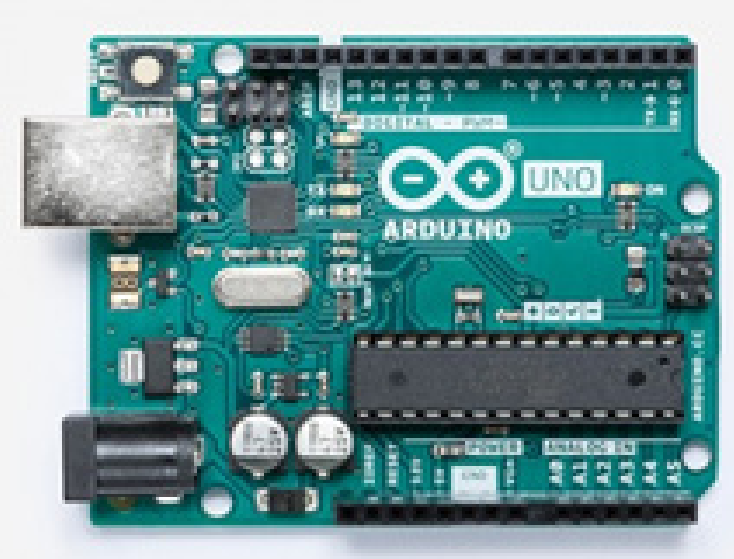

Fig. 3 Moduli Arduino UNO

Një tjetër burim tensioni prej $12 \mathrm{~V}$ do të lidhet me Arduino UNO dhe do të jetë burimi kryesor për modulin tonë, në të cilin ndodhet mikrokontrollori dhe mbajtësi i memories. Nisur nga Arduino do të dalin një set jumperash, të cilët do të mundësojnë lidhjen e duhur me sensorin ultrasonik, e më pas me portat e duhura që të mund t'i shfrytëzojmë gjatë punës. Gjithashtu, një tjetër seri jumperash është i lidhur me kontrollorin orientues për drejtimin horizontal të sensorit.

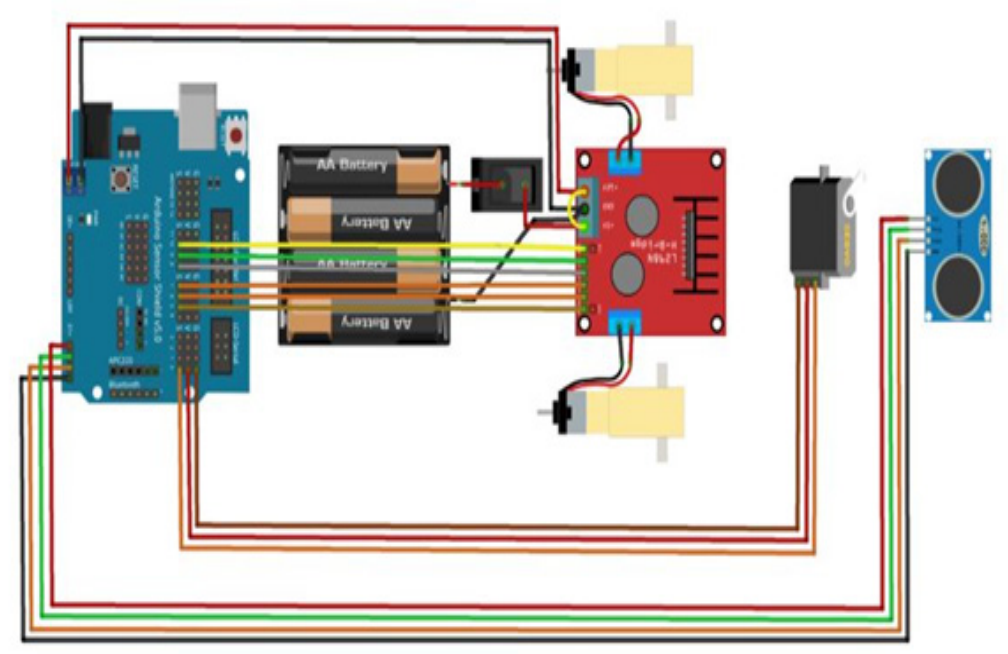

Fig. 4 Skema përfundimtare 


\section{KONTROLLI AUTOMATIK NË ROBOTIKË}

\section{Programimi}

Moduli Arduino programohet nëpërmjet gjuhës së programimit Arduino [5]. Sensori ultrasonik do të marrë dhe analizojë të dhëna gjatë një cikli të përsëritur 50 herë në sekondë, fusha e tij e 'pamjes' është $40 \mathrm{~cm}$ dhe për sa kohë që nuk do të ndeshet me ndonjë pengesë, roboti do të vazhdojë lëvizjen drejt.Në momentin e gjetjes së një objekti me distancë më të afërt se $7 \mathrm{~cm}$, prototipi do të ndalojë lëvizjen, sensori ultrasonik me anë të modulit kthehet 90 gradë në të majtë, nëse analizon që distanca është e lirë atëherë edhe motorrat përgjegjës për rrotullimin e rrotave do të analizojnë një kthim prej 90 gradësh.Nëse sensori pas rrotullimit në të majtë has një pengesë, logjika e programit është që ai të kthehet - 90 gradë në të majtë dhe nëse distanca prej $7 \mathrm{~cm}$ është e lirë atëherë do të realizohet rrotullimi në të djathtë.

Nëse në të dyja rastet dështojnë, pra nuk ka asnjë distancë të lirë, atëherë sipas programit roboti do të realizojë një lëvizje të reversuar prej-180 gradësh, ku do t’i mundësojë kthimin mbrapsh.

Për sa kohë që ky cikël komandash do të funksionojë, roboti do të jetë i aftë të lëvizë i pavarur dhe të shmangë pengesat në mënyrë automatike.

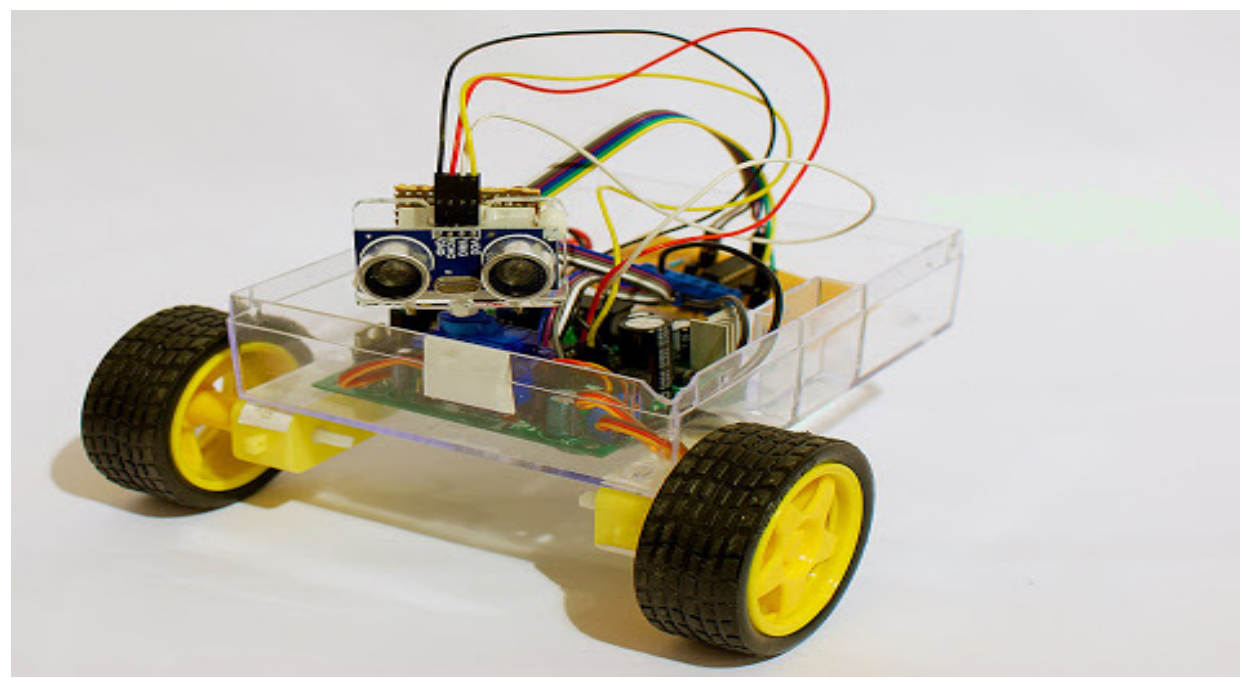

Fig. 5 Paraqitja e robotit

\section{Rekomandime}

Roboti ynë është thjeshtë një prototip, normalisht në të ardhmen mund të zhvillohet edhe më tej. Mund të fillojmë duke shtuar 1 ose 2 sensorë ultrasonike më shumë dhe kjo do t'i jepte robotit tonë një 'shikim' më të gjerë e për të kuptuar më mirë ambientin që e rrethon. 
Enea Kote, Artur Prendi

Gjithashtu, mund t'i shtohen edhe sisteme të tjera, të cilat do mund ta bënin robotin tonë të telekomandueshëm me valë Bluetooth, ose një tjetër sensor LED, që do mund të drejtonte nëpërmjet dritës.

Një mundësi e mirë do të ishte dhe vendosja e një ekrani LCD, pasi do mundësonte leximin në kohë reale në ekran të shpejtësise së robotit dhe distancën ndaj objekteve rrethuese.

\section{Referenca}

1. Fraden J., Handbook of Modern Sensors, Springer, $4^{\text {th }}$ edition, 2010.

2. Mutinda M. G., Kamweru P. C., Arduino Uno, Ultrasonic Sensor HC-SR04 Motion Detector with Display of Distance in the LCD, International Journal of Engineering Research \& Technology, 2020, Vol. 9, Issue 5, http://dx.doi.org/10.17577/IJERTV9IS050677

3. https://create.arduino.cc/projecthub/projects/tags/robot

4. Evans B., Beginning Arduino Programming (Technology in Action), Apress, 2011.

5. S. Monk, Programming Arduino: Getting Started with Sketches, McGraw-Hill Education TAB; 2nd edition, 2016. 